\title{
STUDY ON LOAD-DEFLECTION RELATIONSHIP OF RECYCLED SELF-COMPACTING CONCRETE FILLED STEEL TUBULAR COLUMNS SUBJECTED TO ECCENTRIC COMPRESSION
}

\author{
Feng Yu ${ }^{1}$, Long Chen ${ }^{1}$, Yuan Fang ${ }^{1,}{ }^{*}$, Jun-jie Jiang ${ }^{1}$, Shi-long Wang ${ }^{1}$ and Zheng-yi Kong ${ }^{1}$ \\ ${ }^{1}$ Department of Civil Engineering and Architecture, Anhui University of Technology, Maanshan, China \\ * (Corresponding author: E-mail: fyuan86@126.com)
}

\section{A B S T RA C T}

Behaviors of recycled self-compacting concrete filled steel tubular (RSCCFST) columns under eccentric compression were experimentally investigated in this paper. The influences of the recycled coarse aggregate (RCA) replacement ratios, lengthdiameter ratios, eccentricities, and concrete strength were examined. According to the tests, the RSCCFST columns demonstrated a satisfying performance under the eccentric loads. The failure modes of short and long RSCCFST columns are drum-like bending and flexural buckling, respectively. Large replacement ratio of RCA and length-diameter ratio would reduce the member stiffness and increase the yielding and ultimate deflections; while the variation of concrete strength has little effect on the deflections. Therefore, to improve the member bearing capacity, the most effective way is to reduce the RCA replacement ratio, length-diameter ratio and increase the concrete strength. Furthermore, based on the fiber strip method, a numerical analysis approach for conveniently evaluating the load-deflection relationship of the RSCCFST columns was developed. The load-deflection curves of the specimens were calculated with the numerical method and compared with the test data. The verifications illustrated the proposed method has good accuracy and can be adopted in engineering practices.
ART I CLE H I S T O RY

$\begin{array}{ll}\text { Received: } & \text { 22 November } 2018 \\ \text { Revised: } & \text { 18 January } 2019 \\ \text { Accepted: } & \text { 25 January } 2019\end{array}$

\section{KE YW O R D S}

Concrete filled steel tube; Recycled self-compacting concrete;

Replacement ratio of RCA; Length-diameter ratio;

Eccentricity

Copyright $\odot 2019$ by The Hong Kong Institute of Steel Construction. All rights reserved.

\section{Introduction}

Due to rapid urbanization and city renewal, increasing use of natural aggregates and deposit of construction waste result in severe environmental paroblems. To resolve this issue, the recycled coarse aggregate (RCA) using the crushed waste concrete has been proposed [1].

According to previous research [2-6], RCA would influence the splitting tensile strength, flexural strength and durability of recycled aggregate concrete. Gupta [7] conducted an experiment to investigate the mechanical properties of recycled aggregate concrete showing the tensile and flexural strength of recycled aggregate concrete can be improved by increasing the water-cement ratio, and the capacity of the RCA concrete with the high water-cement ratio is greater than the conventional concrete. Kou et al. [8] and Tam et al. [9] found that the mechanical properties of the concrete with the recycled aggregate immersed in sulfide, chloride and polyvinyl alcohol were better than ordinary concrete. Xiao et al. [10] investigated the dynamic performance of the recycled concrete frame, which indicated that the structure with a higher replacement ratio of RCA, ratio between the mass of recycled coarse aggregate and total coarse aggregate, had a good seismic resistance.

The self-compacting concrete (SCC) could improve both concrete performance and construction safety due to its good homogeneity, fluidity and compactness [11,12]. Silva et. al. [13], Kenai et. al. [14] and Zoran et. al. [15] indicated that the properties of recycled self-compacting concrete (RSCC) was excellent with an appropriate RCA replacement ratio, which demonstrated RSCC has a potential to be a useful material in civil engineering.

Furthermore, the concrete-filled steel tube (CFST) has been widely used due to its extraordinary bearing capacity, ductility and low construction costs [16-18]. It has a superior performance under compression [19-22], dynamic load [23] and fire [24]. From this point of view, the recycled concrete filled steel tubular (RCFST) column was proposed. Mohanraj et al. [25] experimentally investigated the axial compressive behavior of RCFST columns that indicated the ultimate bearing capacity of RCFST columns was higher than conventional reinforced concrete and reinforced recycled concrete columns with $10 \%$ less cost of concrete. Yang and Han [26] examined the performance of RCFST columns under eccentric compression. Results showed that the failure modes of RCFST columns were similar to the ordinary CFST columns, i.e., the overall bucking failure. Tang et al. [27] analyzed the behavior of RCFST columns under cyclic loading, where the RCFST columns exhibited excellent deformation capacity and ductility compared with ordinary CFST columns.

However, the compactness of the core concrete, relating to the bearing capacity, in the composite structure is difficult to guarantee. Muciaccia et al. [28] illustrated that the good compactness and homogeneity could be obtained under the self-gravity of SCC in CFST. Mahgub et al. [29] conducted an experiment on axially loaded SCC filled elliptical steel tubular columns demonstrating that the composite columns with large length-diameter ratio has overall buckling failure mode and low bearing capacity.

Although a lot of investigations on RCFST and self-compacting concrete filled steel tube (SCCFST) have been carried out, little research focuses on the mechanical properties of RSCCFST columns. In this study, twenty-one RSCCFST columns were tested to investigate the member performance under eccentric compression. The influences of the RCA replacement ratio, lengthdiameter ratio, eccentricity and concrete strength on the load-deflection relationship were discussed. A convenient numerical analysis approach for evaluating the column capacity is presented.

\section{Experimental Program}

\subsection{Preparation of Specimens}

To comparatively investigate the RSCCFST column performance, twentyone specimens with various properties, replacement ratios of RCA, lengthdiameter ratios, eccentricities and concrete strength grades, were tested. The parameters of the specimens are given in Table 1 . Both ends of the tubes were polished, flatted and wielded with $300 \mathrm{~mm} \times 300 \mathrm{~mm} \times 10 \mathrm{~mm}$ steel plates. During the specimen fabrication, after the bottom end plate was connected to the steel tube, the RSCC was poured without vibration. A plastic film was used to temporarily seal the upper end of the specimen to reduce the water evaporation. When the core RSCC was set, the plastic film was removed, and the upper steel plate was welded to the top of the specimen.

\subsection{Material properties}

Q235 steel was used to make the straight seamless outer tube. The material properties of the steel measured from the coupon test are provided in Table 2. The RSCC consisted of coarse aggregates (RCA and ordinary graded gravel), continuously graded fine aggregates (sand and fly-ash), P. O 42.5 cement, tap water, and Polycarboxylate acid superplasticizer. RCA was obtained by crushing the waste C20 C60 concrete blocks. The sieve analysis of RCA was performed according to the Chinese standard JGJ 52-2006 [30]. The particle sizes of RCA and ordinary graded gravel were $5 \mathrm{~mm}-31.5 \mathrm{~mm}$. The components of RSCC and the mechanical properties determined from the specified method in Chinese Regulation JGJ/T283-2012 [31] are shown in Table 3.

\subsection{Test setup and procedure}

The experiments were conducted on the hydraulic compression testing machine. The detailed test setup and strain measuring points were shown in Fig. 1 . 
Two linear variable displacement transducers (LVDTs) were employed to monitor the column's axial deformation. Another three LVDTs were horizontally arranged at $0.25 \mathrm{~L}, 0.5 \mathrm{~L}$, and $0.75 \mathrm{~L}$ height to determine the lateral column deflections. For the short column, eight strain gauges were evenly arranged at the column mid-height to measure the axial and circumferential strains, see Fig. 1(a). For the long column, twenty-four strain gauges were glued evenly at $0.25 \mathrm{~L}, 0.5 \mathrm{~L}$, and $0.75 \mathrm{~L}$, see Fig. 1 (c)

The experiments were initiated with the load-controlled loading scheme with the rate of $50 \mathrm{kN} / \mathrm{min}$. After the axial load reached approximately $85 \%$ of the estimated ultimate bearing capacity, the displacement-controlled loading scheme with the rate of $0.5 \mathrm{~mm} / \mathrm{min}$ was adopted.

Table 1

Parameters of specimens

\begin{tabular}{|c|c|c|c|c|c|c|c|c|}
\hline $\begin{array}{l}\text { Specimen } \\
\text { ID }\end{array}$ & $\mathrm{D} / \mathrm{mm}$ & $\mathrm{t} / \mathrm{mm}$ & $\mathrm{L} / \mathrm{mm}$ & $\gamma_{1 \%}$ & $\mathrm{e} / \mathrm{mm}$ & $\mathrm{e} / \mathrm{r}$ & $\mathrm{L} / \mathrm{D}$ & $\begin{array}{c}\text { Concrete } \\
\text { number }\end{array}$ \\
\hline RSCSE-1 & 140 & 3.63 & 500 & 0 & 20 & 0.30 & 3.57 & S1/C30 \\
\hline RSCSE-2 & 140 & 3.63 & 500 & 0 & 40 & 0.60 & 3.57 & $\mathrm{~S} 1 / \mathrm{C} 30$ \\
\hline RSCSE-3 & 140 & 3.63 & 500 & 0 & 60 & 0.90 & 3.57 & $\mathrm{~S} 1 / \mathrm{C} 30$ \\
\hline RSCSE-4 & 140 & 3.63 & 500 & 50 & 20 & 0.30 & 3.57 & $\mathrm{~S} 2 / \mathrm{C} 30$ \\
\hline RSCSE-5 & 140 & 3.63 & 500 & 50 & 40 & 0.60 & 3.57 & $\mathrm{~S} 2 / \mathrm{C} 30$ \\
\hline RSCSE-6 & 140 & 3.63 & 500 & 50 & 60 & 0.90 & 3.57 & S2/C30 \\
\hline RSCSE-7 & 140 & 3.63 & 500 & 100 & 20 & 0.30 & 3.57 & $\mathrm{~S} 3 / \mathrm{C} 30$ \\
\hline RSCSE-8 & 140 & 3.63 & 500 & 100 & 40 & 0.60 & 3.57 & $\mathrm{~S} 3 / \mathrm{C} 30$ \\
\hline RSCSE-9 & 140 & 3.63 & 500 & 100 & 60 & 0.90 & 3.57 & $\mathrm{~S} 3 / \mathrm{C} 30$ \\
\hline RSCSE-10 & 140 & 3.63 & 500 & 100 & 20 & 0.30 & 3.57 & S4/C50 \\
\hline RSCSE-11 & 140 & 3.63 & 500 & 100 & 40 & 0.60 & 3.57 & S4/C50 \\
\hline RSCSE-12 & 140 & 3.63 & 500 & 100 & 60 & 0.90 & 3.57 & S4/C50 \\
\hline RSCSE-13 & 140 & 3.63 & 500 & 100 & 20 & 0.30 & 3.57 & S5/C60 \\
\hline RSCSE-14 & 140 & 3.63 & 500 & 100 & 40 & 0.60 & 3.57 & S5/C60 \\
\hline RSCSE-15 & 140 & 3.63 & 500 & 100 & 60 & 0.90 & 3.57 & S5/C60 \\
\hline RSCSE-16 & 140 & 3.63 & 1000 & 100 & 20 & 0.30 & 7.14 & S4/C50 \\
\hline RSCSE-17 & 140 & 3.63 & 1000 & 100 & 40 & 0.60 & 7.14 & S4/C50 \\
\hline RSCSE-18 & 140 & 3.63 & 1000 & 100 & 60 & 0.90 & 7.14 & S4/C50 \\
\hline RSCSE-19 & 140 & 3.63 & 1500 & 100 & 20 & 0.30 & 10.71 & S4/C50 \\
\hline RSCSE-20 & 140 & 3.63 & 1500 & 100 & 40 & 0.60 & 10.71 & S4/C50 \\
\hline RSCSE-21 & 140 & 3.63 & 1500 & 100 & 60 & 0.90 & 10.71 & S4/C50 \\
\hline
\end{tabular}

Note: RSCSE indicates eccentrically loaded columns, $D, L, t$, and $\gamma$ are the measured steel tube outside diameter, length, thickness, and the replacement ratio of RCA, respectively, $r$ and $e$ are the radius of concrete and the eccentricity, respectively.

Table 2

The main material properties of the steel tube

\begin{tabular}{ccccc}
\hline $\begin{array}{c}\text { Tube } \\
\text { thickness } \\
(\mathrm{mm})\end{array}$ & $\begin{array}{c}\text { Yield } \\
\text { strength } \\
(\mathrm{MPa})\end{array}$ & $\begin{array}{c}\text { Tensile } \\
\text { strength } \\
(\mathrm{MPa})\end{array}$ & $\begin{array}{c}\text { Young's modulus } \\
\left(10^{5} \mathrm{MPa}\right)\end{array}$ & $\begin{array}{c}\text { Poisson's } \\
\text { ratio }\end{array}$ \\
\hline 3.63 & 233.23 & 295.68 & 2.00 & 0.297 \\
\hline
\end{tabular}

\section{Experimental results and analysis}

\subsection{Failure modes}

The failure process of the eccentrically loaded RSCCFST columns contained three stages as elasticity, elastoplasticity and plasticity. The elastic stage, specimens kept intact. With the deformation increasing, rust on the surface of the outer tubes peeled off gradually. When the load approached the ultimate bearing capacity, the slight crushing noise of the internal RSCC can be heard, and the lateral deformation became apparent. The failure modes of the specimens are shown in Fig. 2, where the eccentrically loaded RSCCFST short columns and long columns presented drum-like bending failure and overall flexural buckling failure modes, respectively.

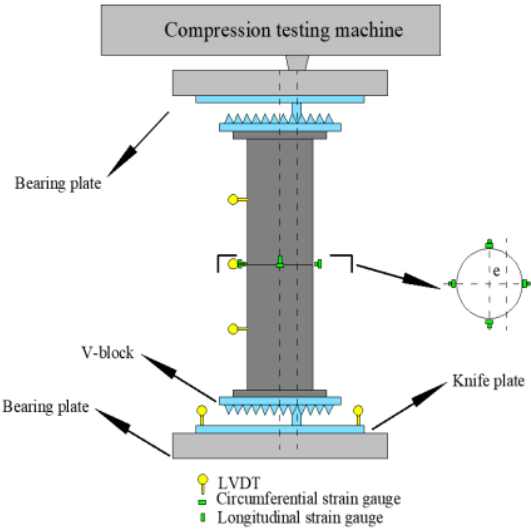

(a) Short column schematic diagram

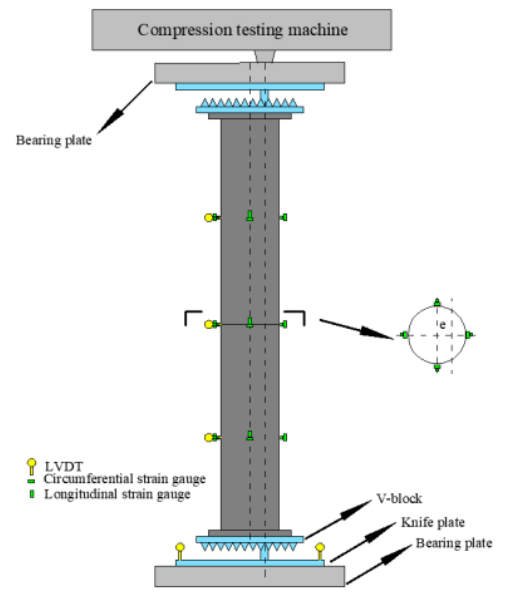

(c) Long column schematic diagram

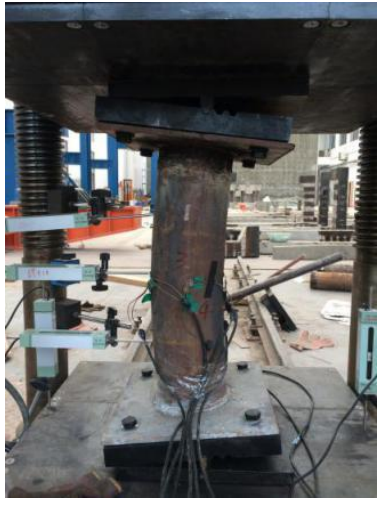

(b) Short column

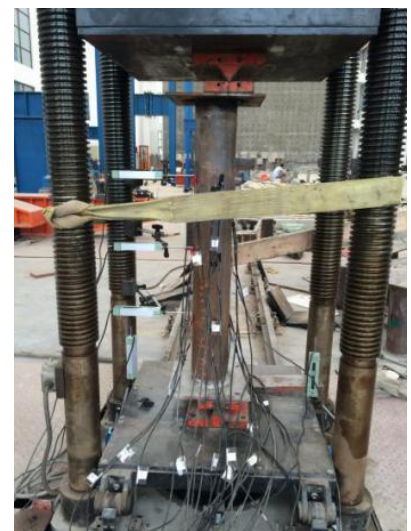

(d) Long column
Fig. 1 Test set up and strain measuring points arrangement

\subsection{Load-deflection relationship analysis}

Load-deflection $(\mathrm{N}-\Delta)$ curves of the specimens are plotted in Fig. 3, where $\mathrm{N}$ stands for the axial load, $\Delta$ is the lateral deflection at mid-height $(0.5 \mathrm{~L})$ of the columns.

The load-deflection curves can be roughly divided into three parts. The first part is the linear phase, where the load and deflection were approximately proportional. In the second part, the nonlinear phase, the relation between the load and deflection became nonlinear. With the load further increased, the specimens almost lost the capacity. The load-deflection curves entered the third part, the horizontal phase.

The yield and ultimate deflections and the displacement ductility coefficient of the RSCCFST specimens are summarized in Table 4.

\subsubsection{Effect of replacement ratio of $R C A$}

The comparison shown in Fig. 3(a) demonstrates the influences of the replacement ratio of RCA. It can be seen the use of RAC would reduce the bearing capacity of RSCCFST columns. This is mainly because the bonding effects between aggregates were weakened by the residual mortar attached on the surface of RCA. This defect decreased the elastic modulus of RSCC and the lateral deflection at the yield strength. However, the displacement ductility coefficient could be increased with a large amount of RCA.

\subsubsection{Effect of length-diameter ratio}

The load-deflection curves of the specimens with different length-diameter ratios are shown in Fig. 3(b). The conception of the length-diameter ratio of CFST is similar to the slender ratio. Member with the high length-diameter ratio has a low initial stiffness, large P- $\delta$ effects and a weak constraint on the inner concrete. Therefore, as shown in the Figure., raising the length-diameter ratio would increase the deflections and decrease the ductility of the RSCCFST columns. 
Table 3

Component of RSCC and measured strength

\begin{tabular}{|c|c|c|c|c|c|c|c|c|c|c|c|}
\hline \multirow{2}{*}{ Number } & \multicolumn{7}{|c|}{ Material usage $/ \mathrm{kg}$} & \multirow{2}{*}{$\begin{array}{c}\text { Cube } \\
\text { compressive } \\
\text { strength } \\
(\mathrm{MPa})\end{array}$} & \multirow{2}{*}{$\begin{array}{c}\text { Axial } \\
\text { compressive } \\
\text { strength. } \\
(\mathrm{MPa})\end{array}$} & \multirow{2}{*}{$\begin{array}{c}\text { Poisson's } \\
\text { ratio }\end{array}$} & \multirow{2}{*}{$\begin{array}{l}\text { Young's } \\
\text { modulus } \\
\left(10^{4} \mathrm{MPa}\right)\end{array}$} \\
\hline & Water & Sand & Cement & Fly ash & $\begin{array}{l}\text { Water } \\
\text { reducer }\end{array}$ & NCA & $\mathrm{RCA}$ & & & & \\
\hline S1 & 210 & 736 & 305 & 144 & 3.143 & 798 & 0 & 36.2 & 29.1 & 0.217 & 2.63 \\
\hline S2 & 210 & 736 & 305 & 144 & 3.143 & 399 & 399 & 34.6 & 27.8 & 0.174 & 2.57 \\
\hline S3 & 210 & 736 & 305 & 144 & 3.143 & 0 & 798 & 33.0 & 26.3 & 0.152 & 2.31 \\
\hline S4 & 176 & 936 & 395 & 151 & 1.638 & 0 & 798 & 53.4 & 42.8 & 0.168 & 2.73 \\
\hline S5 & 164 & 736 & 477 & 113 & 1.770 & 0 & 798 & 61.8 & 49.5 & 0.165 & 3.02 \\
\hline
\end{tabular}

where, $\sigma_{\mathrm{s}}, \varepsilon_{\mathrm{s}}$ are the stress and strain of steel, respectively, $E_{\mathrm{s}}$ is the

\subsubsection{Effect of eccentricity}

The eccentricity inducing the secondary moment would reduce the member yielding and ultimate load capacity. Moreover, the bending moment changes the stress state of the part inner concrete from triaxial axial compress to tension leading to a great drop of its strength. As shown in Fig 3(c), similar to CFST columns, the eccentricity has a negative effect on the capacity and stiffness of RSCCFST columns.

\subsubsection{Effect of concrete strength grade}

The compressive strength of the RSCCFST column is mainly provided by the inner concrete. According to Fig. 3(d), the use of the concrete with high strength improves the bearing capacity of the columns. However, the influences on the lateral deflection and the ductility are not obvious.

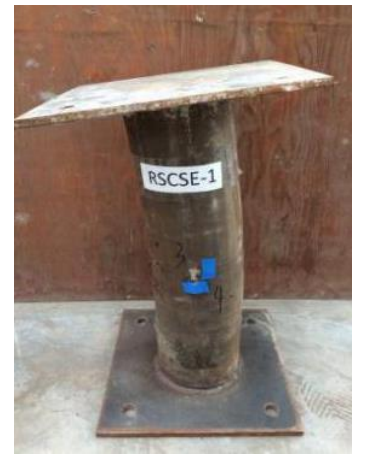

(a) RSCSE-1

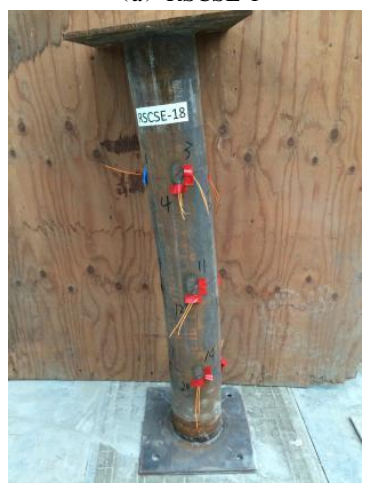

(c) RSCSE-18

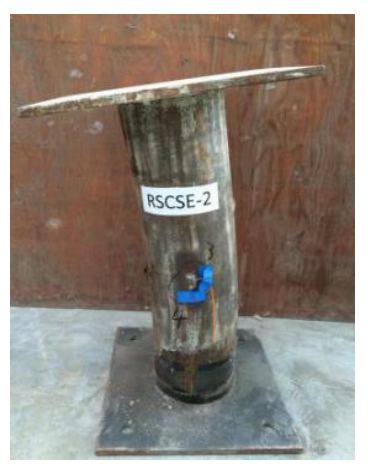

(b) RSCSE-2

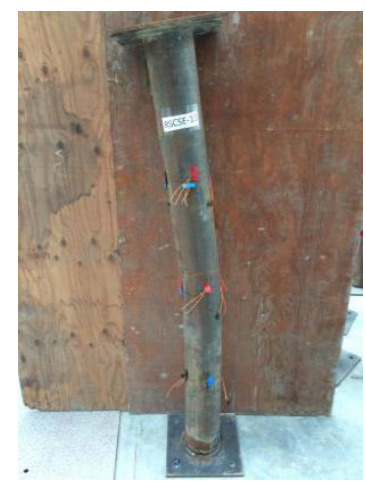

(d) RSCSE-19
Fig. 2 Failure mode of the RSCCFST columns

\section{Numerical analysis of load-deflection relationship}

\subsection{Modelling of steel tube}

The stress-strain relationship of steel is usually generalized as the curve shown in Fig.4, which can be described as $[32,33]$

$$
\sigma_{\mathrm{s}}= \begin{cases}E_{\mathrm{s}} \varepsilon_{\mathrm{s}} & \varepsilon_{\mathrm{s}} \leq \varepsilon_{\mathrm{p}} \\ -A \varepsilon_{\mathrm{s}}^{2}+B \varepsilon_{\mathrm{s}}+C & \varepsilon_{\mathrm{p}}<\varepsilon_{\mathrm{s}} \leq \varepsilon_{\mathrm{y} 1} \\ f_{\mathrm{y}} & \varepsilon_{\mathrm{y} 1}<\varepsilon_{\mathrm{s}} \leq \varepsilon_{\mathrm{y} 2} \\ f_{\mathrm{y}}\left[1+0.6\left(\varepsilon_{\mathrm{s}}-\varepsilon_{\mathrm{y} 2}\right) /\left(\varepsilon_{\mathrm{u}}-\varepsilon_{\mathrm{y} 2}\right)\right] & \varepsilon_{\mathrm{y} 2}<\varepsilon_{\mathrm{s}} \leq \varepsilon_{\mathrm{u}} \\ 1.6 f_{\mathrm{y}} & \varepsilon_{\mathrm{s}}>\varepsilon_{\mathrm{u}}\end{cases}
$$

Young's modulus of steel, $f_{\mathrm{y}}, f_{\mathrm{u}}$ are the yield strength and ultimate strength of steel, $f_{\mathrm{p}}$ is the proportional limit of steel, $\varepsilon_{\mathrm{p}}=0.8 f_{\mathrm{y}} / E_{\mathrm{s}}$ is the strain corresponding to the proportional limit of steel $\varepsilon_{\mathrm{y}_{1}}=1.5 \varepsilon_{\mathrm{p}}$ and $\varepsilon_{\mathrm{y}_{2}}=10 \varepsilon_{p}$ stand for the strain at the starting yield point and the ending yield point, respectively, $\varepsilon_{\mathrm{u}}=100 \varepsilon_{\mathrm{p}}$ is the strain corresponding to the ultimate strength, and $A=0.2 f_{\mathrm{y}}\left(\varepsilon_{\mathrm{y} 1}-\varepsilon_{\mathrm{p}}\right)^{2}, B=2 A \varepsilon_{\mathrm{y} 1}, C=0.8 f_{y}+A \varepsilon_{\mathrm{p}}{ }^{2}-B \varepsilon_{\mathrm{p}}$
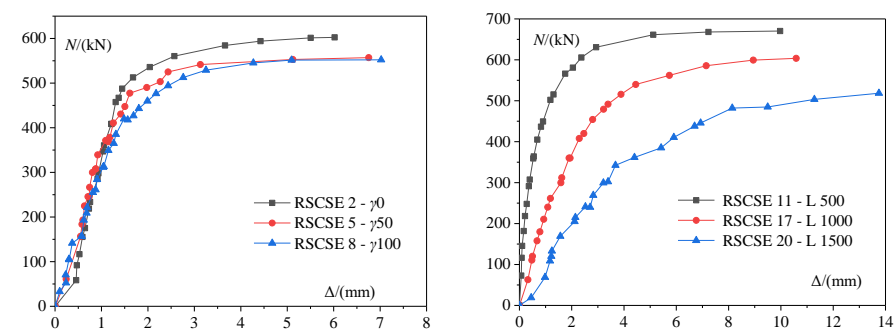

(a) The replacement ratio of $\mathrm{RCA}(e=40 \mathrm{~mm})$

(b) The length-diameter ratio $(e=40 \mathrm{~mm})$

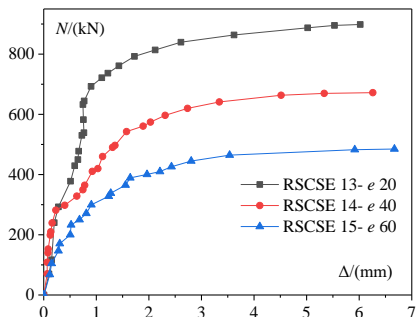

(c) Eccentricity

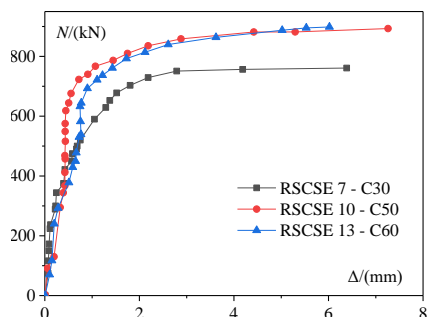

(d) Concrete strength grade
Fig. 3 The effect of four parameters on load-deflection relationship

\subsection{Modelling of RSCC}

Based on the research of Xiao [34] and Han et al. [35], the stress-strain relationship of RSCC including the effects of the RCA is proposed in this study. The stress-strain curve of RSCC under compression is plotted in Fig.5, which can be represented with Eq (2) as

$\frac{\sigma_{\mathrm{c}}}{\sigma_{\mathrm{cp}}}= \begin{cases}g\left(\frac{\varepsilon_{\mathrm{c}}}{\varepsilon_{\mathrm{cp}}}\right)+(3-2 g)\left(\frac{\varepsilon_{\mathrm{c}}}{\varepsilon_{\mathrm{cp}}}\right)^{2}+(g-2)\left(\frac{\varepsilon_{\mathrm{c}}}{\varepsilon_{\mathrm{cp}}}\right)^{3} & \varepsilon_{\mathrm{c}}<\varepsilon_{\mathrm{cp}} \\ \frac{\left(\frac{\varepsilon_{\mathrm{c}}}{\varepsilon_{\mathrm{cp}}}\right)}{h\left(\frac{\varepsilon_{\mathrm{c}}}{\varepsilon_{\mathrm{cp}}}-1\right)^{2}+\left(\frac{\varepsilon_{\mathrm{c}}}{\varepsilon_{\mathrm{cp}}}\right)} & \varepsilon_{\mathrm{c}} \geq \varepsilon_{\mathrm{cp}}\end{cases}$

where, $\sigma_{\mathrm{c}}, \varepsilon_{\mathrm{c}}$ are the compressive stress and strain of RSCC, respectively. $\sigma_{\mathrm{cp}}, \varepsilon_{\mathrm{cp}}$ are the maximum compressive stress and strain of RSCC respectively, $g$ and $h$ are the parameters obtained from the regression analysis of test data as

$$
\begin{aligned}
& g=2.125-1.171 \gamma-0.0035 f \\
& h=3.51 \times 10^{-4} \cdot\left(2.36 \times 10^{-5}\right)^{\left[0.25+(\xi-0.5)^{7}\right]} \cdot\left(f_{\mathrm{c}}-3.2 \gamma\right)^{2}
\end{aligned}
$$

where, $f$ is the axial compressive strength of RSCC, $\gamma$ is the replacement ratio of RCA, $\xi=\left(\mathrm{A}_{\mathrm{s}} f_{\mathrm{y}}\right) /\left(\mathrm{A}_{\mathrm{c}} \beta_{\gamma} f_{\mathrm{ck}}\right)$ is the confinement effect coefficient that considering the influence of the replacement ratio of RCA. 
Table 4

The yield, ultimate deflection and the displacement ductility coefficient

\begin{tabular}{|c|c|c|c|c|c|c|c|c|}
\hline $\begin{array}{l}\text { Specimen } \\
\text { ID }\end{array}$ & $\gamma$ & $\begin{array}{c}\text { Concrete } \\
\text { number }\end{array}$ & $\begin{array}{c}e l \\
\mathrm{~mm}\end{array}$ & $L / D$ & $\begin{array}{l}N / \\
\mathrm{kN}\end{array}$ & $\begin{array}{l}\Delta \mathrm{y} / \\
\mathrm{mm}\end{array}$ & $\begin{array}{c}\Delta \mathrm{u} / \\
\mathrm{mm}\end{array}$ & $\mu_{\Delta}$ \\
\hline RSCSE-1 & 0 & $\mathrm{~S} 1 / \mathrm{C} 30$ & 20 & 3.57 & 819 & 1.51 & 5.02 & 3.32 \\
\hline RSCSE-2 & 0 & $\mathrm{~S} 1 / \mathrm{C} 30$ & 40 & 3.57 & 603 & 2.17 & 6.02 & 2.77 \\
\hline RSCSE-3 & 0 & $\mathrm{~S} 1 / \mathrm{C} 30$ & 60 & 3.57 & 512 & 2.66 & 6.18 & 2.32 \\
\hline RSCSE-4 & 50 & $\mathrm{~S} 2 / \mathrm{C} 30$ & 20 & 3.57 & 776 & 1.08 & 5.54 & 5.13 \\
\hline RSCSE-5 & 50 & $\mathrm{~S} 2 / \mathrm{C} 30$ & 40 & 3.57 & 557 & 1.40 & 6.76 & 4.83 \\
\hline RSCSE-6 & 50 & $\mathrm{~S} 2 / \mathrm{C} 30$ & 60 & 3.57 & 457 & 1.51 & 6.92 & 4.58 \\
\hline RSCSE-7 & 100 & $\mathrm{~S} 3 / \mathrm{C} 30$ & 20 & 3.57 & 761 & 0.90 & 6.39 & 7.10 \\
\hline RSCSE-8 & 100 & $\mathrm{~S} 3 / \mathrm{C} 30$ & 40 & 3.57 & 552 & 1.07 & 7.02 & 6.56 \\
\hline RSCSE-9 & 100 & $\mathrm{~S} 3 / \mathrm{C} 30$ & 60 & 3.57 & 441 & 1.34 & 7.04 & 5.25 \\
\hline RSCSE-10 & 100 & S4/C50 & 20 & 3.57 & 893 & 1.01 & 7.26 & 7.2 \\
\hline RSCSE-11 & 100 & S4/C50 & 40 & 3.57 & 670 & 1.15 & 9.97 & 8.67 \\
\hline RSCSE-12 & 100 & $\mathrm{~S} 4 / \mathrm{C} 50$ & 60 & 3.57 & 504 & 1.38 & 10.93 & 7.92 \\
\hline RSCSE-13 & 100 & S5/C60 & 20 & 3.57 & 898 & 0.75 & 6.02 & 8.02 \\
\hline RSCSE-14 & 100 & S5/C60 & 40 & 3.57 & 672 & 1.00 & 6.26 & 6.22 \\
\hline RSCSE-15 & 100 & S5/C60 & 60 & 3.57 & 585 & 1.28 & 6.67 & 5.21 \\
\hline RSCSE-16 & 100 & $\mathrm{~S} 4 / \mathrm{C} 50$ & 20 & 7.14 & 783 & 1.23 & 9.77 & 7.94 \\
\hline RSCSE-17 & 100 & $\mathrm{~S} 4 / \mathrm{C} 50$ & 40 & 7.14 & 604 & 1.5 & 10.59 & 7.06 \\
\hline RSCSE-18 & 100 & $\mathrm{~S} 4 / \mathrm{C} 50$ & 60 & 7.14 & 431 & 2.20 & 11.01 & 5.0 \\
\hline RSCSE-19 & 100 & S4/C50 & 20 & 10.71 & 748 & 4.03 & 12.51 & 3.10 \\
\hline RSCSE-20 & 100 & S4/C50 & 40 & 10.71 & 518 & 4.60 & 13.75 & 2.98 \\
\hline RSCSE-21 & 100 & $\mathrm{~S} 4 / \mathrm{C} 50$ & 60 & 10.71 & 408 & 4.95 & 14.16 & 2.86 \\
\hline
\end{tabular}

Note: $\Delta_{\mathrm{y}}$ is the deflection at yielding strength, $\Delta_{\mathrm{u}}$ is the deflection at ultimate strength, $\mu_{\Delta}$ is the displacement ductility coefficient.

$A_{s}=2 \pi(r+t / 2) t$ is the cross section area of steel tube in compression zone, $A_{\mathrm{c}}=\pi r^{2} \sin ^{2} \theta$ is the cross section area of internal RSCC in compression zone, $\beta_{\gamma}=1+0.055 \gamma-0.171 \gamma^{2}$ is the replacement ratio of RCA influence coefficient obtained by regression analysis, $f_{\mathrm{ck}}$ is the axial compressive characteristic strength of RSCC. [32]

The stress-strain relationship model for internal RSCC in tension zone is

$\frac{\sigma_{1}}{\sigma_{\mathrm{lp}}}=\left\{\begin{array}{cc}1.2\left(\frac{\varepsilon_{1}}{\varepsilon_{\mathrm{lp}}}\right)-0.2\left(\frac{\varepsilon_{1}}{\varepsilon_{\mathrm{lp}}}\right)^{6} & \varepsilon_{1}<\varepsilon_{\mathrm{lp}} \\ \frac{\left(\frac{\varepsilon_{1}}{\varepsilon_{\mathrm{lp}}}\right)}{0.31 \sigma_{\mathrm{lp}}^{2}\left(\frac{\varepsilon_{1}}{\varepsilon_{\mathrm{lp}}}-1\right)^{1.7}+\left(\frac{\varepsilon_{1}}{\varepsilon_{\mathrm{lp}}}\right)} & \varepsilon_{1} \geq \varepsilon_{\mathrm{lp}}\end{array}\right.$

where, $\sigma_{1}, \varepsilon_{1}$ are the tensile stress and strain of RSCC, respectively. $\sigma_{1 \mathrm{p}}$, $\varepsilon_{\mathrm{lp}}$ are the maximum tensile stress and strain of RSCC, respectively.

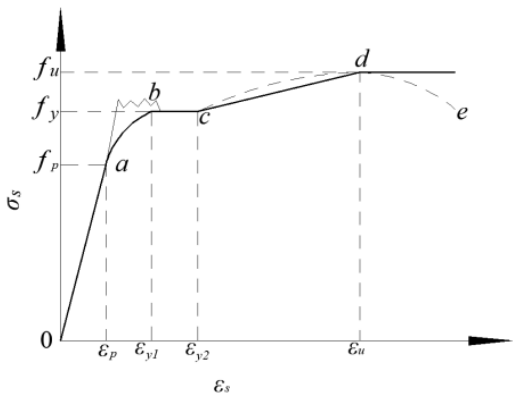

Fig. 4 Stress-strain curve of steel tube

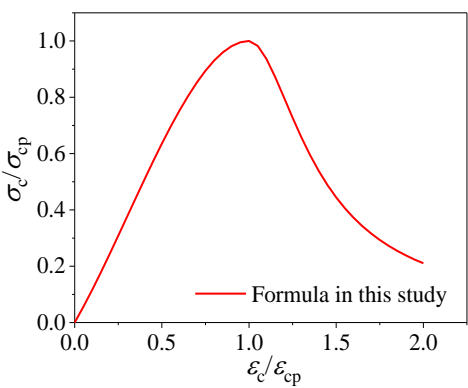

Fig. 5 Stress-strain relationship of RSCC

\subsection{Numerical analysis}

4.3.1. Assumptions

In the numerical analysis of the load-deflection relationship for the RSCCFST columns under eccentric compression, the following calculation assumptions were proposed: (1) The stress-strain relations of steel and RSCC given in Eqs.(1), (2) and (5) are adopted; (2) The RSCCFST column under eccentric loads was simply supported, and the deflection is a half sinusoidal curve; (3) The core RSCC and the outer steel tube work together, and the deformation was coordinated; (4) The shear deformation is ignored; (5) Plane sections remain plane.

\subsubsection{Section fiber model}

According to the assumption (2), the member deflection curve is plotted in Fig. 6 . The section at the middle height is the most critical and will be chosen as the monitoring section. The lateral deflection of the column and the curvature $\phi$ of the section can be calculated as

$y=\Delta \sin \frac{\pi}{L} x$

$\phi=\frac{\pi^{2}}{L^{2}} \Delta$

To evaluate the column deflection, the section internal forces should be accurately obtained, where the finite strip method is adopted. As shown in Fig.7, the cross-section of the specimen is mashed into several strips. Each strip includes a steel tube and a core RSCC unit. By calculating the stress of each fiber, the moment of the section would be determined.

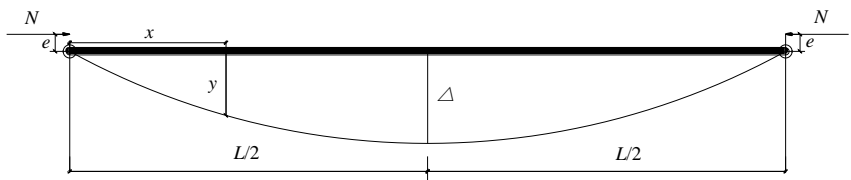

Fig. 6 The deflection curve of the specimen

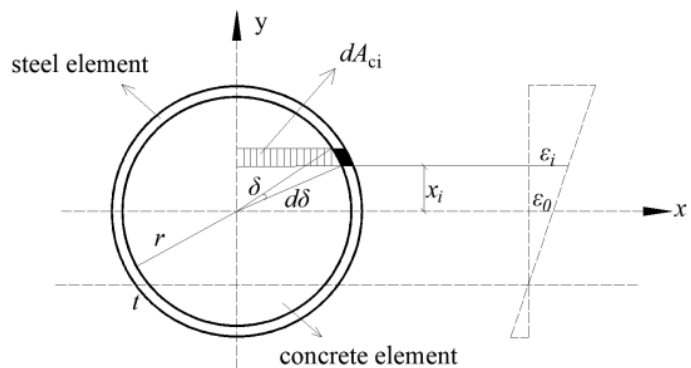

Fig. 7 Element division of sections and strain distribution

\subsubsection{Equilibrium equation}

According to the assumption (5), the strain $\varepsilon_{\mathrm{i}}$ at the center of each strip are 
where, $\varepsilon_{0}$ is the strain at the centroid of cross-section, and $x_{\mathrm{i}}$ is the distance from the center of the strip to the cross-section centroid. The strip stress of the outer steel tube $\sigma_{\mathrm{si}}$ and the core RSCC $\sigma_{\mathrm{ci}}$ can be calculated according to the assumption (1). Based on the section stress, the axial force $N_{\text {in }}$ and bending moment $M_{\text {in }}$ of cross-section can be determined as

$N_{\mathrm{in}}=\sum_{\mathrm{i}}^{\mathrm{n}}\left(\sigma_{\mathrm{ci}} d A_{\mathrm{ci}}+\sigma_{\mathrm{si}} d A_{\mathrm{si}}\right)=N_{\mathrm{i}}$

$M_{\mathrm{in}}=\sum_{\mathrm{i}}^{\mathrm{n}}\left(\sigma_{\mathrm{ci}} x_{\mathrm{i}} d A_{\mathrm{ci}}+\sigma_{\mathrm{si}} x_{\mathrm{i}} d A_{\mathrm{si}}\right)=N_{\mathrm{i}}(e+\Delta)$

\subsubsection{Calculation process}

The numerical analysis approach is proposed to obtain the load-deflection curve of eccentrically loaded RSCCFST columns. The specific processes are: (1) to input the parameters and divide the section into strips; (2) to initialize the deflection, curvature and the strain at the centroid as $\Delta_{0}=0, \phi=0$ and $\varepsilon_{0}=0.01$, respectively; (3) to determine the strip strains $\varepsilon_{\mathrm{i}}$ according to Eq. (8); (4) to determine stress $\sigma_{\mathrm{ci}}$ and $\sigma_{\mathrm{si}}$ at the centroid of different strips based on the material stress-strain relationship; (6) to calculate the axial force $N_{\text {in }}$ and bending moment $M_{\text {in }}$ using Eqs. (9) and (10). If the equilibrium condition $\left|M_{\text {in }} / N_{\text {in }}-e-\Delta\right| \leq 0.01$ was satisfied, output the load $N_{\text {i }}$ and deflection $\Delta_{\mathrm{i}}$; otherwise, adjust the strain $\varepsilon_{0}$ and repeat the steps (3-6); (7) to output the load-deflection $(N-\Delta)$ curves of the RSCCFST columns. The flow chart of the numerical analysis approach was shown in Fig.8.

The $N-\Delta$ curves of the RSCCFST columns under eccentric loads obtained from the experiments and the proposed numerical analysis method are plotted and compared in Fig.9. Results indicated that the calculated value based on the fiber model method agreed well with the experimental results.

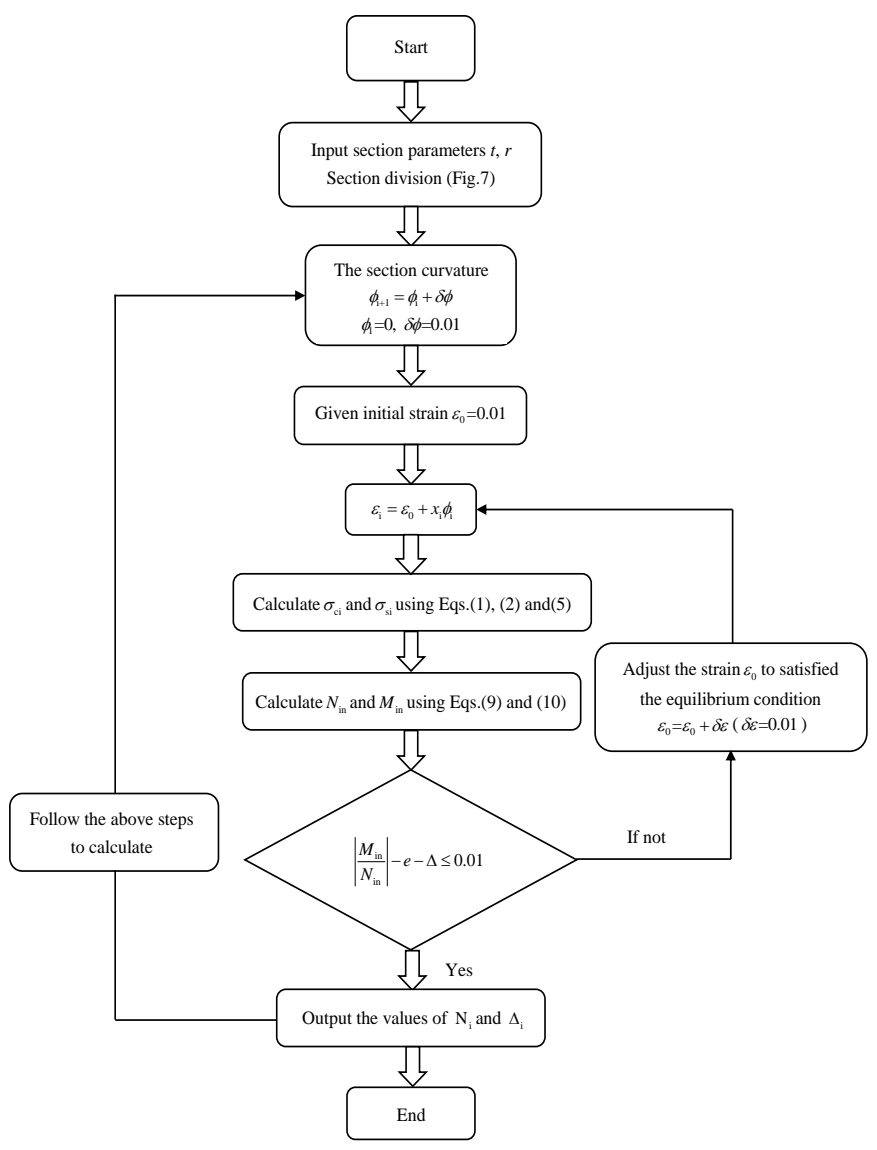

\subsection{Parametric studies}

Parametric study using the proposed numerical analysis method is conducted in this section to investigate the influences of different parameters on the member behavior, including the steel yield strength $f_{\mathrm{y}}$, the steel ratio $\alpha=A_{\mathrm{s}} / A_{\mathrm{c}}$, the steel tube diameter-to-thickness ratio $\mathrm{D} / \mathrm{t}$, the concrete strength grade $f_{\mathrm{c}}$, the length-diameter ratio $\mathrm{L} / \mathrm{D}$, the eccentricity $e$, and the replacement ratio of RCA $\gamma$. Specimens RSCSE-5, RSCSE-7 and RSCSE-8 are employed as the comparative reference. The load-deflection curves of the members with different parameters are shown in Fig.10. Compared to the experimental studies, the influences of the concrete strength, the length-diameter ratio, the eccentricity, and the replacement ratio of RCA predicted by the parametric analysis is the same, which further demonstrates the accuracy of the numerical analysis approach. Fig.10 (a) illustrates the effects of the steel yield stress, where the member with higher $f_{y}$ has a higher bearing capacity because of the stronger confining force provide by the outer steel tube. With the same reason, the increase of the steel ratio or decrease the diameter-to-thickness ratio could enhance the behavior of the members as shown in Fig.10 (b) and Fig.10 (c).

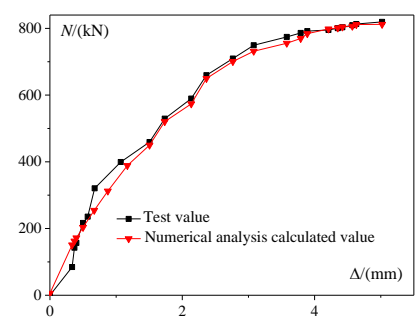

(a) specimen RSCSE-1

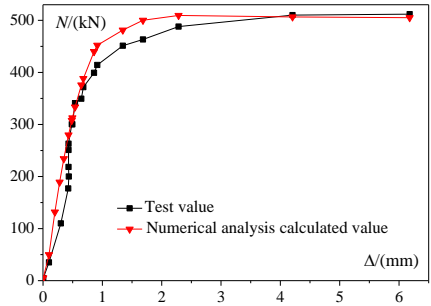

(c) specimen RSCSE-3

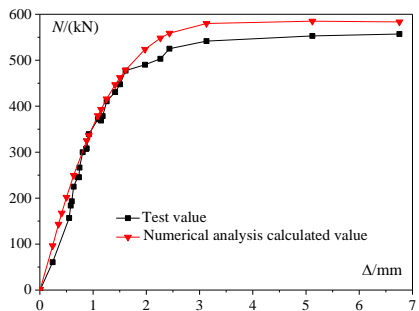

(e) specimen RSCSE-5

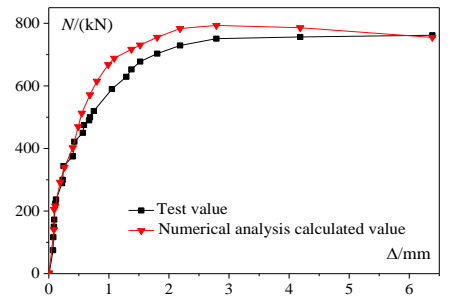

(g) specimen RSCSE-7

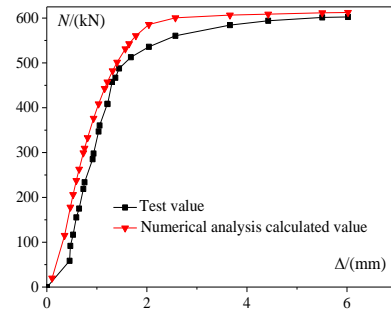

(b) specimen RSCSE-2

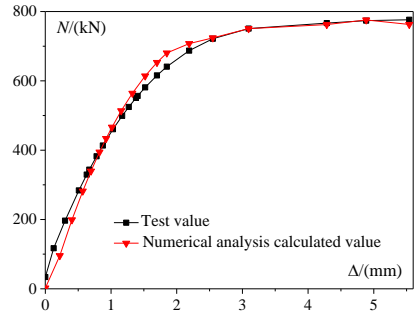

(d) specimen RSCSE-4

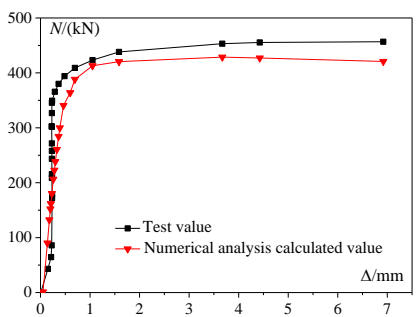

(f) specimen RSCSE-6

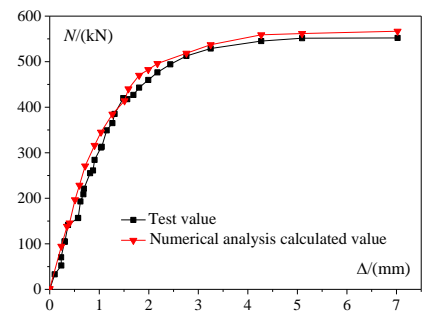

(h) specimen RSCSE-8

Fig. 8 The $N-\Delta$ program flow chart 


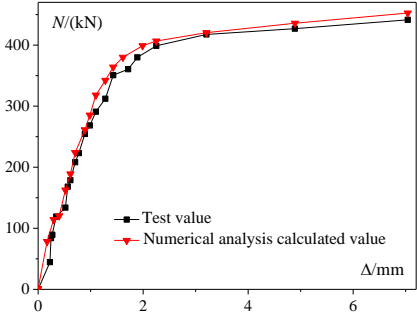

(i) specimen RSCSE-9

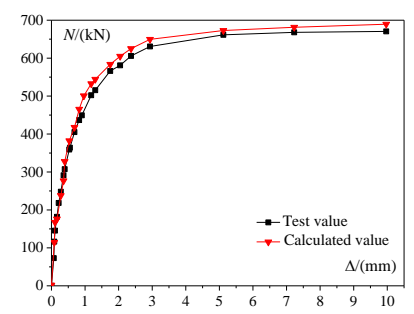

(k) specimen RSCSE-11

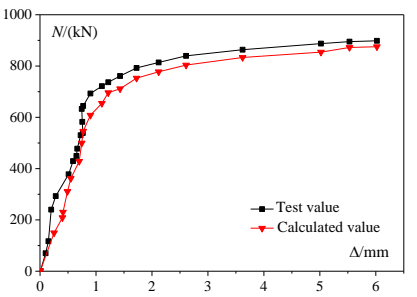

(m) specimen RSCSE-13

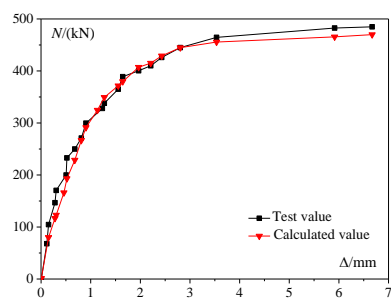

(o) specimen RSCSE-15

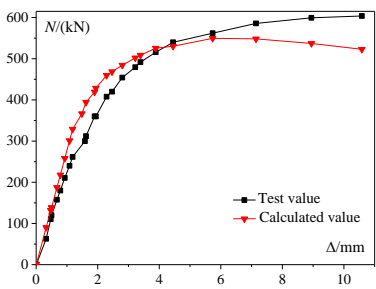

(q) specimen RSCSE-17

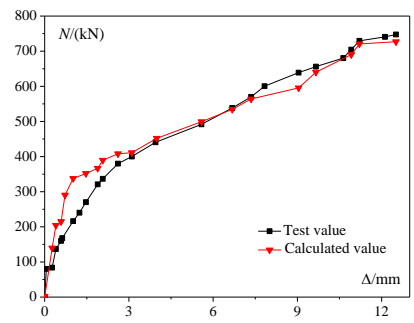

(s) specimen RSCSE-19

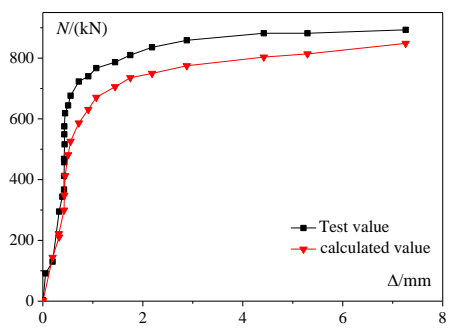

(j) specimen RSCSE-10

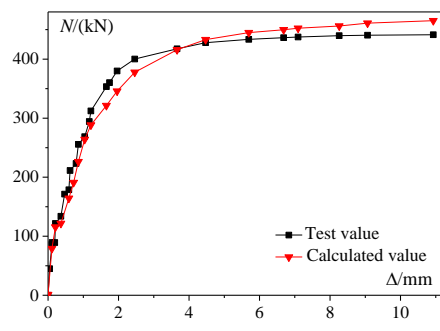

(1) specimen RSCSE-12

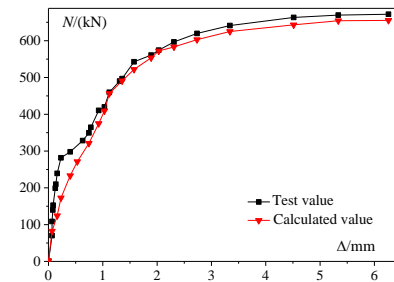

(n) specimen RSCSE-14

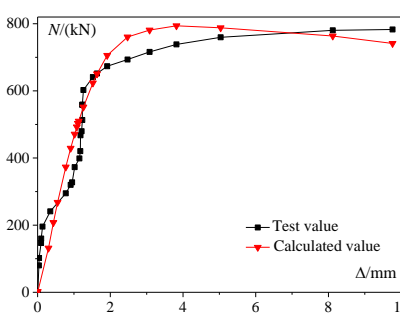

(p) specimen RSCSE-16

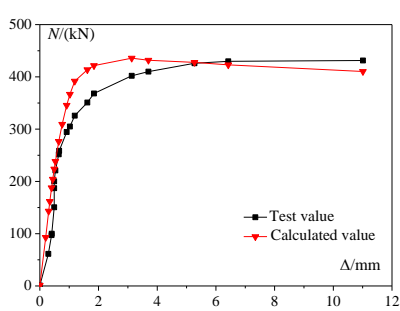

(r) specimen RSCSE-18

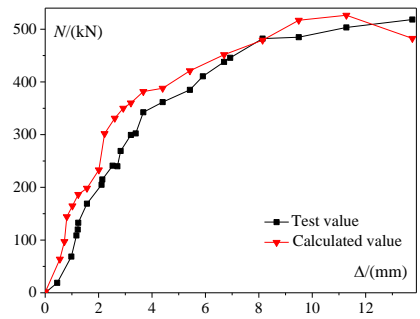

(t) specimen RSCSE-20

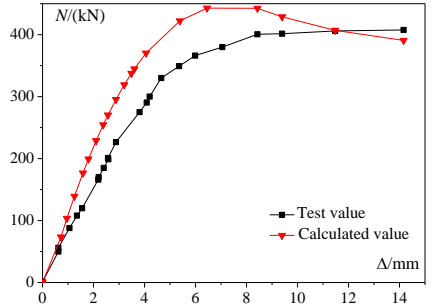

(u) specimen RSCSE-21

Fig. 9 The comparison of $N-\Delta$ curve obtained by numerical analysis and test data

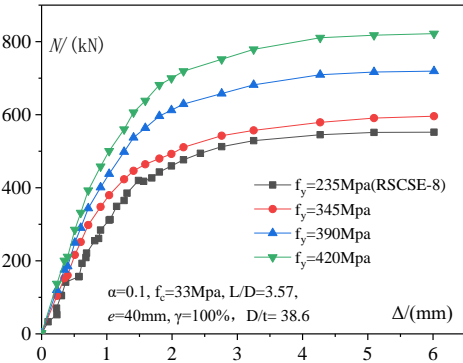

(a) Effect of $f_{\mathrm{y}}$ based on specimen RSCSE-8

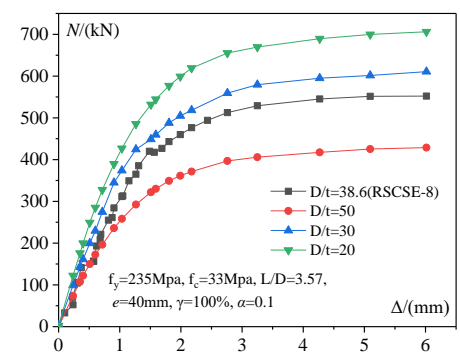

(c) Effect of $D / t$ based on specimen RSCSE-8

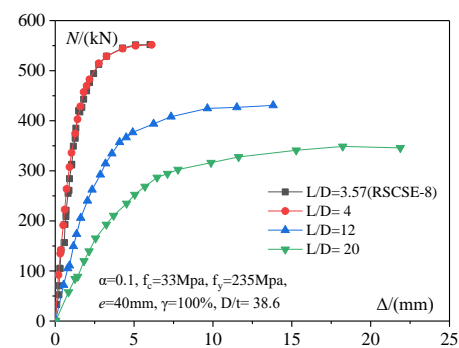

(e) Effect of L/D based on specimen RSCSE-8

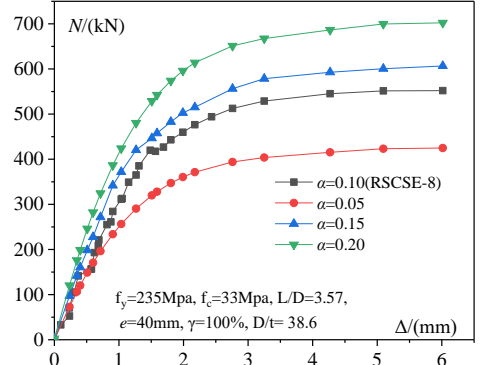

(b) Effect of $\alpha$ based on specimen RSCSE-8

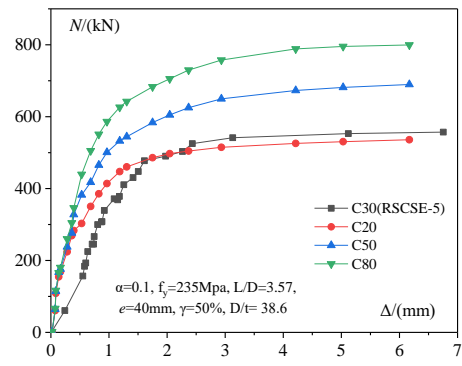

(d) Effect of $f_{c}$ based on specimen RSCSE-5

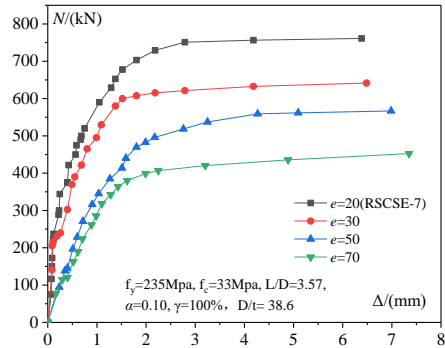

(f) Effect of $e$ based on specimen RSCSE-7

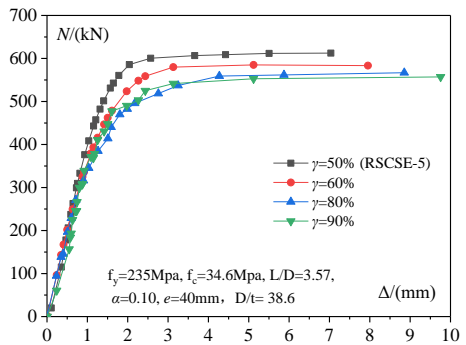

(g) Effect of $\gamma \quad$ based on specimen RSCSE-5

Fig. 10 Load-deflection curve of parametric studies 


\section{Conclusion}

The behavior of eccentrically loaded RSCCFST columns was investigated in this study. The influences of the replacement ratio of RCA, length-diameter ratio, eccentricity, and concrete strength on bearing capacity and deflection were analyzed. The main conclusions can be drawn as

(1) The failure modes of short and long RSCCFST columns under eccentric compression are the drum-like bending failure and overall flexural buckling failure, respectively.

(2) The ultimate bearing capacity of the composite member can be enhanced by reducing the replacement ratio of RCA, length-diameter ratio, eccentricity or increasing the concrete strength.

(3) The rise of the length-diameter ratio or the eccentricity would increase the lateral deflections at the mid-span. Nevertheless, the use of RCA has different effects on the yield and ultimate deflections with the former and latter decreases and increases, respectively.

(4) The member with the low length-diameter ratio, small eccentricity or high RCA replacement ratio has good ductility.

(5) A numerical analysis method for calculating the load-deflection relationship of simply supported eccentrically compressed RSCCFST columns is developed based on the finite strip method. The results obtained from the proposed method are close to the test data.

\section{Acknowledgements}

This work was supported by the National Natural Science Foundation of China (No. 51578001, 51878002, 51608003, and 51008001), Natural Science Foundation granted by Department of Education, Anhui Province (No. KJ2015ZD10 and KJ2018A0046), Key Research and Development Plan of Anhui Province (No. 1704a0802131), and the Outstanding Young Talent Support Program of Anhui Province (No. gxyqZD2016072).

\section{References}

[1] Omary S., Ghorbel E. and Wardeh G., "Relationships between recycled concrete aggregates characteristics and recycled aggregates concretes properties", Construction and Building Materials, 108, 163-174, 2016.

[2] Xiao J.Z., Recycled Concrete, China Architecture \& Building Press, Beijing, 2008.

[3] Gabr A.R. and Cameron D.A., "Properties of recycled concrete aggregate for unbound pavement construction", Journal of Materials in Civil Engineering, 24(6), 754-764, 2013.

[4] Thomas J., Thaickavil N.N. and Wilson P.M., et al, "Strength and durability of concrete containing recycled concrete aggregates. Journal of building engineering", 19, 349-365, 2018

[5] Verian K.P., Ashraf W. and Cao Y., "Properties of recycled concrete aggregate and their influence in new concrete production", Resources Conservation and Recycling, 133, 30-49, 2018.

[6] Sagoe-Crentsil K.K., Brown T. and Taylor A.H., "Performance of concrete made with commercially produced coarse recycled concrete aggregate", Cement and Concrete Research, 31(5), 707-712, 2001.

[7] Gupta S.M., "Strength characteristics of concrete made with demolition waste as coarse aggregate", Proceedings of the International Conference on Recent Development in Structural Engineering, 364-373, 2001.

[8] Kou S.C. and Poon C.S., "Properties of concrete prepared with PVA-impregnated recycled concrete aggregates", Cement and Concrete Composites, 32(8), 649-654, 2010.

[9] Tam V., Tam C.M. and Le K.N., "Removal of cement mortar remains from recycled aggregate using pre-soaking approaches", Resources Conservation and Recycling, 50(1), 82$101,2007$.

[10] Xiao J., Sun Y. and Falkner H., "Seismic performance of frame structures with recycled aggregate concrete", Engineering Structures, 28(1), 1-8, 2006

[11] Manzi S., Mazzotti C. and Bignozzi M.C. et al, "Self-compacting concrete with recycled concrete aggregate: Study of the long-term properties", Construction and Building Materials, $157,582-590,2017$

[12] González-Taboada I., González-Fonteboa B., Martínez-Abella F. and Seara-Paz S., "Evaluation of self-compacting recycled concrete robustness by statistical approach", Construction \& Building Materials, 176, 720-736, 2018.

[13] Silva Y.F., Robayo R.A., Mattey P.E. and Delvasto S., "Properties of self-compacting concrete on fresh and hardened with residue of masonry and recycled concrete", Construction and Building Materials, 124, 639-644, 2016.

[14] Kenai S., Menadi B., Debbih A. and Kadri E.H., "Effect of recycled concrete aggregates and natural pozzolana on rheology of self-compacting concrete", Key Engineering Materials, 600, 256-263, 2014

[15] Zoran Jure Grdic., Gordana A., Toplicic-Curcic., Iva M., Despotovic., Nenad S. and Ristic., "Properties of self-compacting concrete prepared with coarse recycled concrete aggregate", Construction and Building Materials, 24(7), 1129-1133, 2010

[16] Georgios Giakoumelis. and Dennis Lam., "Axial capacity of circular concrete-filled tube columns", Journal of Constructional Steel Research, 60(7), 1049-1068, 2004.

[17] Choi K.K. and Xiao Y., "Analytical studies of concrete-filled circular steel tubes under axial compression", Journal of Structural Engineering-asce, 136(5), 565-573, 2010.

[18] Yang Y.F. and Han L.H., "Behaviour of concrete filled steel tubular (CFST) stub columns under eccentric partial compression", Thin-Walled Structures, 49(2), 379-395, 2011.

[19] Dundu M., "Compressive strength of circular concrete filled steel tube columns", ThinWalled Structures, 56, 62-70, 2012.

[20] Chitawadagi M.V., Narasimhan M.C. and Kulkarni S.M., "Axial strength of circular concrete-filled steel tube columns-doe approach", Journal of Constructional Steel Research, 66(10), 1248-1260, 2010.

[21] Li G., Chen B. and Yang Z. et al, "Experimental and numerical behaviour of eccentrically loaded high strength concrete filled high strength square steel tube stub columns", Thinwalled Structures, 127: 483-499, 2018.
[22] Yang Y.F. and Han L.H., "Concrete filled steel tube (CFST) columns subjected to concentrically partial compression”, Thin-Walled Structures, 50(1), 147-156, 2012.

[23] Susantha K.A.S., Aoki T. and Hattori M., "Seismic performance improvement of circular steel columns using precompressed concrete-filled steel tube", Journal of Constructional Steel Research, 64(1): 30-36, 2008.

[24] Tao Z., Han L.H., Uy B. and Chen X., "Post-fire bond between the steel tube and concrete in concrete-filled steel tubular columns", Journal of Constructional Steel Research, 67(3), 484496, 2011.

[25] Mohanraj E.K., Kandasamy S. and Malathy R., "Behaviour of steel tubular stub and slender columns filled with concrete using recycled aggregates", Journal of the South African Institution of Civil Engineering, 53(2), 31-38, 2011.

[26] Yang Y.F. and Han L.H., "Experimental behaviour of recycled aggregate concrete filled stee tubular columns", Journal of Constructional Steel Research, 62(12), 1310-1324, 2006.

[27] Tang Y.C., Li L.J., Feng W.X., Liu F. and Zhu M., "Study of seismic behavior of recycled aggregate concrete-filled steel tubular columns", Journal of Constructional Steel Research, $148,1-15,2018$.

[28] Muciaccia G., Giussani F., Rosati G. and Mola F., "Response of self-compacting concrete filled tubes under eccentric compression", Journal of Constructional Steel Research, 67(5), 904-916, 2011.

[29] Mahgub M., Ashour A., Lam D. and Dai X., "Tests of self-compacting concrete filled elliptical steel tube columns", Thin-Walled Structures, 110(C), 27-34, 2017.

[30] JGJ52-2006., Standard for technical requirements and test method of sand and crush stone (or gravel) for ordinary concrete, China Architecture \& Building Press, Beijing, China, 2006.

[31] JGJ/T283-2012., Technical specification for application of self-compacting concrete, Chin Architecture \& Building Press, Beijing, China, 2012.

[32] GB50936-2014., Technical code for concrete filled steel tubular structures, China Architecture \& Building Press, Beijing, China, 2014

[33] Zhong S. T., The concrete-filled steel tubular structures (third edition), Tsinghua University Press, Beijing, 2003.

[34] Xiao J.Z., "Experimental investigation on complete stress-strain curve of recycled concrete under uniaxial loading", Journal of Tongji University, 35(11), 1445-1449, 2007.

[35] Han L. H., Concrete filled steel tubular structure-theory and practice, Science Press, Beijing, 2007. 